\title{
Influência de temperatura, luz e giberelina na germinação de sementes de Thlaspi caerulescens J. Presl \& C. Presl (Brassicaceae)
}

\author{
Marcelo de Almeida Guimarães ${ }^{1}$, Deborah de Souza Vidigal ${ }^{2}$, Marcelo Ehlers Loureiro $^{3}$, \\ Denise Cunha Fernandes dos Santos Dias ${ }^{4}$, Amanda Rodrigues Guimarães ${ }^{5}$
}

\begin{abstract}
RESUMO
Thlaspi caerulescens é espécie hiperacumuladora de metais como $\mathrm{Cd}^{2+}, \mathrm{Ni}^{2+}$ e $\mathrm{Zn}^{2+}$, considerada como uma plantamodelo para estudar a acumulação e tolerância a metais pesados. No entanto, a baixa produção de sementes em nossas condições climáticas tornam necessária a determinação de condições que possam maximizar a germinação e o vigor de suas sementes. Para identificar as melhores condições para a germinação, sementes de $T$. caerulescens foram colocadas na presença (15 mmol.m-2. $\mathrm{s}^{-1}$, $8 \mathrm{~h}$ luz/16 h escuro) ou ausência de luz nas temperaturas de 10, 15, 20 e $25^{\circ} \mathrm{C}$, em papel germitest previamente umedecido com solução de ácido giberélico $\left(\mathrm{GA}_{3}\right)$ a $0,05 \%$ ou água destilada. Foram avaliados a porcentagem de germinação (\%G) e o índice de velocidade de germinação (IVG). Maior porcentagem de germinação (66\%) foi observada nos tratamentos com $\mathrm{GA}_{3}$ e temperaturas de 15 e $20^{\circ} \mathrm{C}$, na presença de luz. Maiores valores do IVG foram obtidos com a utilização de $\mathrm{GA}_{3}$ nas temperaturas de 15 e $20^{\circ} \mathrm{C}$, tanto na presença quanto na ausência de luz. Maiores germinação e IVG de T. caerulescens foram observados com uso de $\mathrm{GA}_{3}$ na presença de luz nas temperaturas de 15 e $20^{\circ} \mathrm{C}$.
\end{abstract}

Palavras-chave: Fitorremediação, índice de velocidade de germinação, ácido giberélico.

\section{ABSTRACT \\ Influence of temperature, light and giberelic acid on seed germination of Thlaspi caerulescens J \& C Presl (Brassicaceae)}

Thlaspi caerulescens is a natural zinc (Zn), cadmium (Cd) and nickel (Ni) hyperaccumulator, a model species to study heavy metal hyperaccumulation and tolerance. However, the quick loss of viability under storage and the low production of seeds under non temperate climates justify the need to identify conditions to maximize germination and seed vigor. In order to characterize better conditions for germination, seeds of T. caerulescens were incubated under a photoperiod of $8 \mathrm{~h}$ light $/ 16 \mathrm{~h}$ dark $\left(15 \mathrm{mmol} . \mathrm{m}^{-2} \cdot \mathrm{s}^{-1}\right)$ or in darkness, at temperatures of 10 , 15,20 and $25^{\circ} \mathrm{C}$. The assays were performed with germination paper wetted with $0,05 \%$ giberelic acid or distillated water. Percentage of germination (G\%), and germination speed index (GSI) were evaluated. The highest percentage of germination (66\%) was recorded for the treatments with GA at the temperatures of 15 and $20^{\circ} \mathrm{C}$. The highest GSI was recorded for the treatments with GA at $15^{\circ}$ and $20^{\circ} \mathrm{C}$, independent of the light effect. The highest germination and germination speed index for $T$. caerulescens were obtained with the $\mathrm{GA}_{3}$ treatment, under light, and temperatures between 15 and $20^{\circ} \mathrm{C}$.

Key words: Giberelic acid, phytoremediation, seedling emergence speed index.

Recebido para publicação em abril de 2008 e aprovado em abril de 2010

${ }^{1}$ Engenheiro-Agrônomo, Doutor. Departamento de Ciências Agrárias e do Ambiente/INC-BC, Universidade Federal do Amazonas, Benjamin Constant, 69630-000, Manaus, Amazonas, Brasil.mguimara@hotmail.com

${ }^{2}$ Engenheira-Agrônoma, Mestre. Doutoranda em Fitotecnia, Universidade Federal de Viçosa (UFV), 36570-000, Viçosa, Minas Gerais, Brasil. dsvidigal@gmail.com

${ }^{3}$ Engenheiro-Agrônomo, Ph.D. Departamento de Biologia Vegetal, UFV, 36570-000, Viçosa, MG, Brasil. mehlers@ufv.br

${ }^{4}$ Engenheira-Agrônoma, Doutora. Departamento de Fitotecnia, UFV, 36570-000, Viçosa, MG, Brasil. dcdias@ufv.br

${ }^{5}$ Graduanda. Assistente administrativo do Instituto Federal do Amazonas/IFAM, 69640-000, Benjamin Constant, AM, Brasil. arabranches@yahoo.com.br 


\section{INTRODUÇÃO}

Thlaspi caerulescens (Brassicaceae) é espécie herbácea, bienal, originária dos Alpes Austríacos, sendo encontrada na Europa, América do Norte e Ásia.

Esta espécie tem sido considerada por diversos pesquisadores (Lasat et al., 2000; Pence et al., 2000; Reeves \& Baker, 2000; Salt et al., 2000; Schat et al., 2000; Assunção et al., 2001; Guerinot \& Salt, 2001; Lasat, 2002; Assunção et al., 2003; Cobbet, 2003; Prasad \& Freitas, 2003; Nascimento \& Xing, 2006; Guimarães et al., 2009) como modelo para estudos em fitorremediação, podendo acumular metais como $\mathrm{Cd}^{2+}$, $\mathrm{Ni}^{2+}$ e $\mathrm{Zn}^{2+}$ de 100 até 1.000 vezes mais do que os níveis encontrados no solo. Devido a essa característica, T. caerulescens tem sido largamente utilizada em estudos objetivando identificar as bases moleculares dos mecanismos de tolerância e acumulação de metais pesados. No entanto, a sua origem de clima temperado, o ciclo bienal e a dificuldade da indução floral em nossas condições climáticas resultam em baixa produção de sementes no nosso País, o que dificulta a utilização desta planta modelo para estudos de fitorremediação. Dessa forma, faz-se necessária a avaliação das exigências germinativas da espécie, com o objetivo de se maximizar a germinação e a obtenção de plantas que possam ser utilizadas para o desenvolvimento de estudos e/ou até mesmo para fitorremediação.

Em estudos sobre germinação, fatores como dormência, disponibilidade de água, temperatura, luz e oxigênio podem afetar significativamente os resultados (Carvalho \& Nakagawa, 2000).

A temperatura é um fator que influencia as reações bioquímicas que regulam o metabolismo necessário para iniciar o crescimento do embrião e, em consequência, a porcentagem e a velocidade de germinação (Carvalho \& Nakagawa, 2000). A temperatura ótima para a germinação é aquela na qual a semente expressa o seu potencial máximo em originar plântulas normais no menor tempo possível (Mayer \& Poljakoff-Mayber, 1989). As espécies, no entanto, apresentam comportamento variável quanto à temperatura de germinação, sendo a faixa de 20 a $30{ }^{\circ} \mathrm{C}$ considerada ideal para a maioria das espécies tropicais e subtropicais (Borghetti \& Ferreira, 2004; Borghetti, 2005).

De acordo com Metivier (1986), para espécies de clima temperado, como T. caerulescens, as sementes precisam de exposição a uma temperatura crítica, às vezes por um período considerável, antes de serem capazes de germinar. Essa temperatura, usualmente baixa, não está relacionada com a temperatura ótima para a germinação, mas é requerida para a superação da dormência. Esse tratamento com baixa temperatura, conhecido como estratificação, leva a mudanças fisiológicas e metabólicas.
Além da temperatura a luz pode ser considerada fator importante na germinação de sementes. A luz é necessária para a germinação de espécies denominadas fotoblásticas positivas, enquanto as fotoblásticas negativas germinam melhor quando há limitação de luz, existindo ainda as indiferentes, que não apresentam sensibilidade à luz (Taiz \& Zeiger, 2004).

Outro importante fator a ser considerado é a disponibilidade de água para a embebição das sementes (Guimarães et al., 2008). A umidade do susbtrato é fundamental para desencadear o processo de germinação, pois a hidratação dos tecidos da semente amolece o tegumento e reativa o metabolismo do embrião e tecido de reserva, permitindo a difusão dos reguladores de crescimento e, consequentemente, a ativação dos sistemas enzimáticos. Com isso, ocorrem a degradação, a translocação e a assimilação das reservas, resultando no crescimento do embrião (Marcos Filho, 2005). Um dos reguladores de crescimento essenciais à germinação é a giberelina, que atua na síntese de enzimas-chaves essenciais à degradação das reservas, com destaque para a $\alpha$-amilase (Taiz \& Zeiger, 2004). No entanto, respostas variadas e contrastantes à aplicação de ácido giberélico ( $\left(\mathrm{GA}_{3}\right)$ na germinação de sementes têm sido verificadas (Macchia et al., 2001; Vieira et al., 2002; Bezerra et al., 2006).

Trabalhos sobre germinação de sementes de $T$. caerulescens são escassos. Assim, procurou-se avaliar o efeito de diferentes temperaturas, da luz e do ácido giberélico na germinação de sementes dessa espécie.

\section{MATERIAL E MÉTODOS}

O trabalho experimental foi conduzido no Laboratório de Pesquisas em Sementes do Departamento de Fitotecnia na Universidade Federal de Viçosa (UFV), em Viçosa, Minas Gerais. As sementes de T. caerulescens foram produzidas em condições de ambiente controlado na Universidade de Purdue, nos Estados Unidos, em 2002. Elas foram colhidas e beneficiadas após ser verificado o ciclo completo das plantas, sendo estas submetidas à ausência de água para facilitar a colheita das sementes, as quais foram acondicionadas em tubos Falcon de $10 \mathrm{~mL}$, na ausência de luz e em temperatura de 21 a $23^{\circ} \mathrm{C}$, onde permaneceram por cerca de cinco anos, até serem doadas para a realização deste experimento. As sementes foram distribuídas em delineamento inteiramente casualizado, em esquema fatorial 4 × 2 × 2 (quatro temperaturas x presença ou ausência de luz x umedecimento do susbstrado com água ou giberelina), com quatro repetições de 25 sementes. As sementes foram semeadas sobre duas folhas de papel germitest, umedecidas com 6,0 mL de água destilada ou de solução de ácido giberélico ( $\left(\mathrm{GA}_{3}\right)$ a 0,05\%, em recipiente gerbox. As caixas foram tampadas e mantidas em câma- 
ras de germinação reguladas a 10, 15, 20 e $25^{\circ} \mathrm{C}$, em presença e ausência de luz. Na presença de luz, adotou-se o regime de 8 horas de luz e 16 horas sem luz, com lâmpadas fluorescentes de luz branca fria, com densidade de fluxo luminoso de $15 \mathrm{mmol} \cdot \mathrm{m}^{-2} \cdot \mathrm{s}^{-1}(15 \mathrm{~W})$. Nos tratamentos em ausência de luz, as caixas gerbox foram cobertas com papel-alumínio. Quando necessário, o reumedecimento do susbtrato foi feito sempre com água destilada. Todas as atividades realizadas para o tratamento em ausência de luz ocorreram em condições de baixa luminosidade. Foram feitas avaliações diárias, durante 21 dias, do número de sementes germinadas, adotando-se como critério de germinação a protrusão da raiz primária (1 mm). Foram calculados a porcentagem de germinação e o índice de velocidade de germinação (IVG), conforme Maguire (1962). Empregou-se o teste de Tukey, a 5\% de probabilidade, para comparação entre as médias, utilizando-se o programa SAEG (Ribeiro Junior, 2001).

\section{RESULTADOS E DISCUSSÃO}

Os resultados de porcentagem de germinação das sementes de $T$. caerulescens em diferentes temperaturas, presença e ausência de luz, com a utilização de giberelina $\left(\mathrm{GA}_{3}\right)$ e água $\left(\mathrm{H}_{2} \mathrm{O}\right)$ para a germinação estão apresentados na Tabela 1. Verificou-se que os maiores valores de germinação (66\%) foram obtidos quando as sementes foram colocadas para germinar na temperatura de 15 ou $20^{\circ} \mathrm{C}$, na presença de luz e com a utilização do $\mathrm{GA}_{3}$. De maneira geral, os valores de germinação obtidos quando se utilizou $\mathrm{GA}_{3}$ foram superiores àqueles com umedecimento apenas em água. Na ausência de luz e presença de GA, maior germinação foi observada nas temperaturas de 10 , 15 e $20^{\circ} \mathrm{C}$, e $10{ }^{\circ} \mathrm{C}$ quando essas foram colocadas para germinar em água. A germinação mais baixa foi encontrada nas sementes submetidas à temperatura de $10{ }^{\circ} \mathrm{C}$, umedecidas com água e na presença de luz (14\%).

Ferreira \& Ranal (1999), trabalhando com couve-damalásia (Brassica chinensis var. parachinensis (L.H. Bailey) Sinskaya), mostraram que, durante a germinação, essas sementes de brássicas são indiferentes à luz. Entretanto, esse comportamento não é característico de todas as brássicas. Sementes de Brassica chinensis L. mantidas por 14 dias em regime de temperaturas alternadas de 20 e $30^{\circ} \mathrm{C}$ por 16 e 8 horas, respectivamente, não germinam no escuro (Ellis et al., 1989).

Em relação ao vigor, avaliado pelo índice de velocidade de germinação (Tabela 2), verificaram-se também resultados superiores nas sementes embebidas em substrato umedecido com $\mathrm{GA}_{3}$, nas temperaturas de 15 e $20^{\circ} \mathrm{C}$, tanto na presença (1,52 e 1,68, respectivamente) quanto na ausência de luz (1,45 e 1,67, respectivamente), quando comparado às temperaturas de 10 e $25^{\circ} \mathrm{C}$ e aos substratos umedecidos com água. $\mathrm{O}$ menor índice de velocidade de germinação foi encontrado nas sementes submetidas à temperatura de $10^{\circ} \mathrm{C}$, umedecidas com água e na presença de luz $(0,24)$, e na temperatura de $25^{\circ} \mathrm{C}$, umedecidas com $\mathrm{GA}_{3}$ e na ausência de luz.

Baskin et al. (1989), ao estudarem a germinação de sementes da espécie Thlaspi arvense L. submetidas a temperaturas alternadas, observaram que as maiores porcentagens de germinação, 80 e 100\%, respectivamente, ocorreram em temperaturas alternadas de $15-6$ e $20-10{ }^{\circ} \mathrm{C}$. No entanto, para as temperaturas alternadas de $30-15^{\circ} \mathrm{C}$ e $35-$ $20{ }^{\circ} \mathrm{C}$, esses pesquisadores observaram as menores porcentagens de germinação (15 e 64\%, respectivamente). Os resultados obtidos neste trabalho aproximam-se daqueles apresentados por Baskin et al. (1989), que, apesar de terem trabalhado com outra espécie (Thlaspi arvense L.), obtiveram temperaturas ótimas de germinação próximas às encontradas para T. caerulescens.

No caso de $T$. caerulescens, a temperatura ótima parece estar na faixa de 15 a $20^{\circ} \mathrm{C}$, observando-se efeito positivo de $\mathrm{GA}_{3}$ e da luz. Nas temperaturas de 10 e $25{ }^{\circ} \mathrm{C}$, respectivamente inferior e superior à ótima, observou-se redução da porcentagem e da velocidade de germinação (Tabelas 1 e 2). Segundo Hendricks \& Taylorson (1976), baixas temperaturas durante o processo de germinação podem reduzir as taxas metabólicas até que as vias essenciais no início do processo germinativo não possam mais operar. Por outro lado, de acordo com Vidaver \& Hsiao (1975), altas temperaturas podem induzir à dormência secundária, ou até mesmo à perda da viabilidade das sementes, promovida pelo estresse térmico.

No presente trabalho, os resultados demonstraram que para as sementes de $T$. caerulescens o uso de $\mathrm{GA}_{3}$ foi benéfico, por promover maiores porcentagens de germi-

Tabela 1. Porcentagem de germinação de sementes de Thlaspi caerulescens, na presença e ausência de luz, sob quatro regimes de temperatura e duas substâncias de umedecimento.

\begin{tabular}{|c|c|c|c|c|c|c|c|c|}
\hline \multirow{2}{*}{ Tratamento de luz } & \multicolumn{4}{|c|}{ Embebição em água } & \multicolumn{4}{|c|}{ Embebição em GA 3} \\
\hline & $10^{\circ} \mathrm{C}$ & $15^{\circ} \mathrm{C}$ & $20^{\circ} \mathrm{C}$ & $25^{\circ} \mathrm{C}$ & $10^{\circ} \mathrm{C}$ & $15^{\circ} \mathrm{C}$ & $20^{\circ} \mathrm{C}$ & $25^{\circ} \mathrm{C}$ \\
\hline Presença & $14 \mathrm{~dB}$ & $29 \mathrm{cB}$ & $44 \mathrm{bA}$ & $43 \mathrm{bA}$ & $49 \mathrm{bA}$ & $66 \mathrm{aA}$ & 66 aA & $42 \mathrm{bA}$ \\
\hline Ausência & $55 \mathrm{aA}$ & $37 \mathrm{bA}$ & $31 \mathrm{bB}$ & $10 \mathrm{cB}$ & 56 aA & $60 \mathrm{aB}$ & $60 \mathrm{aB}$ & $39 \mathrm{bA}$ \\
\hline
\end{tabular}

Médias seguidas pela mesma letra (maiúscula nas colunas e minúscula nas linhas) não diferem entre si pelo teste de Tukey a 5\% de probabilidade.

Rev. Ceres, Viçosa, v. 57, n.3, p. 372-376, mai/jun, 2010 
Tabela 2. Índice de velocidade de germinação de sementes de Thlaspi caerulescens, na presença e ausência de luz, sob quatro regimes de temperatura e duas substâncias de umedecimento.

\begin{tabular}{|c|c|c|c|c|c|c|c|c|}
\hline \multirow{2}{*}{ Tratamento de luz } & \multicolumn{4}{|c|}{ Embebição em água } & \multicolumn{4}{|c|}{ Embebição em GA 3} \\
\hline & $10^{\circ} \mathrm{C}$ & $15^{\circ} \mathrm{C}$ & $20^{\circ} \mathrm{C}$ & $25^{\circ} \mathrm{C}$ & $10^{\circ} \mathrm{C}$ & $15^{\circ} \mathrm{C}$ & $20^{\circ} \mathrm{C}$ & $25^{\circ} \mathrm{C}$ \\
\hline Presença & $0,24 \mathrm{eB}$ & $0,72 \mathrm{~dB}$ & $1,20 \mathrm{bcA}$ & $0,73 \mathrm{dA}$ & $0,83 \mathrm{cdA}$ & $1,52 \mathrm{abA}$ & $1,68 \mathrm{aA}$ & $0,87 \mathrm{cdA}$ \\
\hline Ausência & $0,91 \mathrm{bA}$ & $0,94 \mathrm{bA}$ & $0,83 \mathrm{bB}$ & $0,14 \mathrm{cB}$ & 0,86 bA & 1,45 aA & $1,67 \mathrm{aA}$ & $0,62 \mathrm{bB}$ \\
\hline
\end{tabular}

Médias seguidas da mesma letra (maiúscula nas colunas e minúscula nas linhas) não diferem entre si pelo teste de Tukey a $5 \%$ de probabilidade.

nação e maiores índices de velocidade de emergência quando se empregaram as temperaturas de 10,15 e $20^{\circ} \mathrm{C}$, em comparação ao uso de água destilada. Já na temperatura de $25^{\circ} \mathrm{C}$, não houve diferença significativa entre a germinação em substrato umedecido com água e com $\mathrm{GA}_{3}$ em presença de luz.

Diversos autores afirmaram que ocorre aumento na atividade da amilase com a embebição de sementes em $\mathrm{GA}_{3}$ quando comparada à embebição em água (Mayer \& Poljakoff-Mayber, 1989; Bewley \& Black, 1994; Vieira et al., 2002). A $\alpha$-amilase é a principal enzima relacionada ao processo de germinação das sementes, sendo ela a principal responsável pela degradação dos grãos de amido que compõem a reserva da semente. Mayer \& PoljakoffMayber (1989) demonstraram que o $\mathrm{GA}_{3}$ exerce importante papel na germinação de sementes, uma vez que está envolvido na quebra de dormência e no controle da hidrólise de reservas, as quais são essenciais para o crescimento do embrião.

\section{CONCLUSÃO}

O uso de $\mathrm{GA}_{3}$ na presença de luz nas temperaturas de 15 e $20^{\circ} \mathrm{C}$ é eficiente para a maximização da germinação de sementes de Thlaspi caerulescens.

\section{AGRADECIMENTOS}

Ao Conselho Nacional de Pesquisa Científica e Tecnológica (CNPq), pelo apoio financeiro; à Universidade Federal de Viçosa, pela disponibilização da estrutura física; e ao Professor Doutor David Edward Salt, da Universidade de Purdue nos Estados Unidos, pela doação das sementes.

\section{REFERÊNCIAS}

Assunção AGL, Martins PD, De Folter S, Vooijs R, Schat H \& Aarts MGM (2001) Elevated expression of metal transporter genes in three accessions of the metal hyperaccumulator Thlaspi caerulescens. Plant, Cell \& Environment, 24:217-226.

Assunção AGL, Schat H \& Aarts MGM (2003) Thlaspi caerulescens, an attractive model species to study heavy metal hyperaccumulation in plants. New Phytologist, 159:351-360.

Baskin JM, Carol C \& Baskin C (1989) Role of temperature in regulating timing of germination in soil seed reserves of Thlaspi arvense L. Weed Research, 29:317-326.
Bewley JD \& Black M (1994) Seeds: physiology of development and germination. $2^{\text {nd }}$ ed. New York, Plenum Press. 445p.

Bezerra AME, Medeiros Filho S, Bruno RL \& Momenté VG (2006) Efeito da pré-embebição e aplicação de ácido giberélico na germinação de sementes de macela. Revista Brasileira de Sementes, 28:185-190.

Borghetti F (2005) Temperaturas extremas e a germinação das sementes. In: Nogueira RMC (Ed.) Estresses Ambientais: danos e benefícios em plantas. Recife, Universidade Feederal Rural de Pernambuco, Imprensa Universitária, p.207-218.

Borghetti F \& Ferreira AG (2004) Interpretação de resultados de germinação. In: Ferreira AG \& Borghetti F (Orgs.) Germinação: do básico ao aplicado. Porto Alegre, ARTMED, p.209-222.

Carvalho NM \& Nakagawa J (2000) Sementes: ciência, tecnologia e produção. $4^{\text {nd }}$ ed. Jaboticabal, FUNEP. 588p.

Cobbet C (2003) Heavy metals and plants - model systems and hyperacumulators. New Phytologist, 159:289-293.

Ellis RH, Hong TD \& Roberts EH (1989) Quantal response of seed germination in seven genera of Cruciferae to white light of varying photon flux density and photoperiod. Annals of Botany, 63:145-158.

Ferreira WR \& Ranal MA (1999) Germinação de sementes e crescimento de plântulas de Brassica chinensis l. var. parachinensis (Bailey) Sinskaya (couve-da-malásia). Pesquisa Agropecuária Brasileira, 34:353-361.

Guerinot ML \& Salt DE (2001) Fortified foods and phytoremediation. Two sides of the same coin. Plant Physiology, 125:164-167.

Guimarães MA, Dias DCFS \& Loureiro ME (2008) Hidratação de sementes. Revista Trópica - Ciências Agrárias e Biológicas, 2:31-39.

Guimarães MA, Gustin J \& Salt DE (2009). Reciprocal grafting separates the role of the root and shoot in zinc hyperaccumulation in Thlaspi caerulescens. New Phytologist, 184:323-329.

Hendricks SB \& Taylorson RB (1976) Variation in germination and amino acid leakage of seeds with temperature related to membrane phase change. Plant Physiology, 58:7-11.

Lasat MM (2002) Phytoextraction of toxic metals: A review of biological mechanisms. Journal of Environmental Quality, 31:109-120.

Lasat MM, Pence NS, Garvin DF, Ebbs SD \& Kochian LV (2000) Molecular physiology of zinc transport in the $\mathrm{Zn}$ hyperaccumulator Thlaspi caerulescens. Journal of Experimental Botany, 51:71-79.

Macchia M, Angelini LG \& Ceccarini L (2001) Methods to overcome seed dormancy in Echinacea andustifolia DC. Scientia Horticultural, 89:317-324.

Maguire JD (1962) Speed of germination-aid in selection and evaluation for seedling emergence and vigor. Crop Science, 2:176-177.

Marcos Filho J (2005) Fisiologia de sementes de plantas cultivadas. $1^{\text {a }}$ ed. Piracicaba, FEALQ. 495p. 
Mayer AM \& Poljakoff-Mayber A (1989) The germination of seeds. $4^{\text {nd }}$ ed. Toronto, Pergamon Press. 270p.

Metivier JR (1986) Citocininas e giberelinas. In: Ferri MG (Ed.) Fisiologia vegetal. São Paulo, EDUSP, p.93-162.

Nascimento CWA \& Xing B (2006) Phytoextraction: A review on enhanced metal availability and plant accumulation. Scientia Agricola, 63:299-311.

Pence NS, Larsen PB, Ebbs SD, Letham DLD, Lasat MM, Gavin DF \& Kochian LV (2000) The molecular physiology of heavy metal transporter in the $\mathrm{Zn} / \mathrm{Cd}$ hyperaccumulator Thlaspi caerulescens. Proceedings of the National Academy of Science, 97:4956-4960

Prasad MNV \& Freitas HMO (2003) Metal hyperaccumulation in plants - Biodiversity prospecting for phytoremediation technology. Eletronic Journal of Biotechnology, 6:285-321.

Reeves RD \& Baker AJM (2000) Phytoremediation of toxic metals. John Wiley \& Sons, New York, p.193-229.

Ribeiro Junior JI (2001) Análises estatisticas no SAEG. Vicosa, Universidade Federal de Vicosa. 301p.
Salt DE, Kramer U, Smith RD \& Raskin I (2000). The role of root exsudates in nickel hyperaccumulation and tolerance in accumulator and nonaccumulator species of Thlaspi. In: Terry N \& Bañuelos G (Eds.). Phytoremediation of contaminated soil and water. Boca Raton, Lewis Publishers. p.189-200.

Schat H, Llugany M \& Bernhard R (2000) Metal-specific patterns of tolerance, uptake and transport of heavy metals in hyperaccumulating and non-hyperaccumulating metallophytes. In: Terry $\mathrm{N}$ \& Bañuelos $\mathrm{G}$ (Eds.). Phytoremediation of contaminated soil and water. Boca Raton, Lewis Publishers. p.171-188.

Taiz L \& Zeiger E (2004) Fisiologia vegetal. $3^{\text {rd }}$ ed. Porto Alegre, Artmed, 719 p.

Vidaver W \& Hsiao AI (1975) Secondary dormancy in light sensitive lettuce seeds incubated anaerobically or at elevated temperature. Canadian of Botany, 53:2557-2560.

Vieira AR, Vieira MGGC, Fraga AC, Oliveira JA \& Santos CD (2002) Action of gibberellic acid $\left(\mathrm{GA}_{3}\right)$ on dormancy and activity of $\alpha$-amylase in rice seeds. Revista Brasileira de Sementes, 24:43-48. 